\title{
Sixty percent of small coffee farms have suitable socio-economic and environmental locations in Rwanda
}

\author{
Adrie Mukashema ${ }^{1,2}$ - Tom Veldkamp ${ }^{2}$ - Sherif Amer ${ }^{2}$
}

Accepted: 22 March 2016 / Published online: 26 April 2016

(C) The Author(s) 2016. This article is published with open access at Springerlink.com

\begin{abstract}
Evaluating crop suitability is usually based on traditional land approaches in many countries, using only agroecological zoning and soil data. However, land use is also controlled by socio-economic and other biophysical factors. It is actually unknown how coffee suitability is influenced by such socio-economic and biophysical factors. Therefore, here, we studied all known factors that influence coffee production in Rwanda using an inventory of small holder coffee fields, including at least 200 coffee trees. We identified 29 potential factors, including demography, and environmental factors such as climate, soil and topography. These factors were reduced to 17 variables explaining $86 \%$ of the total dataset variability, by factor analysis. The dataset was subsequently stratified into ten agro-ecological zones, yielding regional models that explain regional variability of coffee field density up to $54 \%$. Regional models show that $60 \%$ of the actual coffee farms are located in suitable locations.
\end{abstract}

Keywords Coffee Arabica · Location model · Regional planning $\cdot$ Land use system $\cdot$ Climate change

Tom Veldkamp

a.veldkamp@utwente.nl

1 Rwanda Natural Resources Authority (RNRA), P.O. Box 433, Kigali, Rwanda

2 Faculty of Geo-Information Science and Earth Observation (ITC), University of Twente, P.O. Box 217, 7500

AE Enschede, The Netherlands

\section{Introduction}

Sustainable production of perennial crops such as coffee, tea and cacao in small holder systems, is often a function of human decisions based on location factors, local habits and traditions. These decisions are also influenced by economic demographic and infrastructural factors that can be very dynamic in space and time (Lambin et al. 2001). Quite often perennial crop distribution has a historical component, reflecting past conditions including competition with other crops and land use functions (Veldkamp et al. 2001). Therefore, simplistic relationships explaining spatial crop distribution are rarely found. Interestingly, land evaluation approaches using only agro-ecological zones and soil information are still often used to identify locations for crop expansion (Verdoodt and van Ranst 2006). In order to allow more adaptive land use planning it is essential to understand all underlying location factors that explain perennial crop distribution patterns, including the socio-economic factors (Verburg and Veldkamp 2001). Perennial cash crops in particular are important because they are often the least dynamic cropping system for small holders, generating revenues for farmers and countries.

One of the primary cash crops in Rwanda is coffee, but the question which factors govern its precise geographic pattern remains unanswered. There are of course general relationships with climate, soil and local management (Nzeyimana et al. 2013). But these simple relationships do not explain the current coffee yields nor field density distribution across the country. There are two important coffee area inventories for Rwanda, one is the national census (Nsengiyumva 2009), and the other is an image-based inventory (Mukashema et al. 2014) for all fields with more than 200 coffee trees. At the district level, these inventories have a satisfactory $92 \%$ fit.

Rwanda is the most densely populated country in Africa with 415 pers. $/ \mathrm{km}^{2}$ and a total population of 10.5 million in 
2012 (National Institute of Statistics of Rwanda (NISR 2012). Coffee competes with food crops for the limited land available. Agricultural land (including coffee) take up $54.2 \%$ of the total country territory, the remaining $45.8 \%$ comprise of forest $(28.8 \%$ ), wetlands and water bodies (11\%) (Nyandwi et al. 2016) and urban areas (6\%). As with other cropping systems, the spatial distribution of coffee is a function of environmental drivers (soil, climate and topography) and human drivers (demography, infrastructure, technology and institutions) Veldkamp \& Fresco 1997; Verbist et al. 2005; Hernandez-Martinez et al. 2009). Up to now, suitability for coffee cultivation in Rwanda was only assessed at the level of agro-ecological zone which is a highly aggregate spatial scale (Verdoodt and Van Ranst 2006). Recently, a more detailed soil-based approach using kriging and multi-criteria analysis was developed (Nzeyimana et al. 2014). Both approaches did not include neither socio-economic factors nor the potential dynamic climate factors making both approach not sensitive for the rapid changing Rwandan socio-economic conditions and the expected climate change. The later can be significant in the nearby future as illustrated by Nyandwi et al. (2016) who demonstrated that an increase of $1 \%$ in annual temperature can cause a net wetland area decline by $12 \%$, making these areas suitable for other land use.

It is our objective to analyse the spatial coffee field distribution using the new high resolution coffee map (Mukashema et al. 2014) and using available biophysical and socioeconomic factors that co-determine coffee cultivation locations in Rwanda. When these relationships are known, we will explore how sustainable the current coffee location distribution is and identify potential new suitable locations for coffee production.

\subsection{Historical background of coffee distribution in Rwanda}

According to local reports, the first coffee fields were established by missionaries in Nyundo (northwest) in 1903 and in Mibilizi (southwest) in 1904. Official government involvement began in the 1930s with the Belgian colonial government's coffee campaigns (Boudreaux and Ahluwalia 2009; Murekezi 2009). Under these policies, government authorities built nurseries and supplied seeds, but they also forced Rwandan farmers to plant coffee trees. Coffee cultivation slowly became accepted by the population and gradually spread over the country. Farmers established small coffee fields often surrounded by larger banana fields. By 1930, the expansion slowed down due to famine. After World War II, the coffee area expanded again due to the higher coffee price on the global market. In 1946, an estimated total of eight million coffee trees (about $3200 \mathrm{ha}$ ) was reached. After independence (1962), the government of Rwanda continued the policy of requiring farmers to grow coffee and with the implementation of a 10-year coffee plan in the period 1950 1960, together with a resettlement plan, coffee areas expanded from 12,710 ha in 1964 to 23,930 ha by 1970 . Farmers were also forbidden to interplant other crops with coffee (Boudreaux and Ahluwalia 2009). In 1974, the World Bank supported the expansion of coffee growing a alongside Lake Kivu, causing an increase of coffee acreage increased to 31, 900 ha by 1981 . The Government built coffee nurseries and supplied seeds all over the country to facilitate farmers' access to the selected variety of Bourbon coffee Arabica (Verwimp 2003). During the worldwide coffee crisis of the late 1980s, however, prices tumbled and caused a slowdown of coffee expansion in Rwanda. With their drop in income, farmers were tempted to shift towards production of other cash crops such as bananas, but this was forbidden by Rwandan law, and with an extensive local control system in place, only a few thousand coffee trees were uprooted. The expansion of coffee cultivation areas resumed from 2000 onwards and continues to date mainly at the expense of forest land (UNEP 2011).

Based on recent coffee mapping (Mukashema et al. 2014) and the agricultural census, we know (see Fig. 1) that the western region is the main coffee-growing zone covering $4.4 \%$ of the arable land at the Kivu lake shore and Imbo zones followed by Impala zone (2.9\%), then the central and eastern plateaus $(1.5 \%)$ and Mayaga and Bugesera in southeast $(1.2 \%)$. The Buberuka highlands and high plains of the volcano zones are currently not used for growing coffee.

\subsection{Characteristics of coffee locations in Rwanda}

Coffee in Rwanda is currently grown under temperature conditions ranging from 14.2 to $23.8^{\circ} \mathrm{C}$ in areas with annual rainfall varying between $700 \mathrm{~mm}$ in the East and $2120 \mathrm{~mm}$ in the Congo-Nile watershed divide and the Buberuka highlands. Coffee areas are characterised by a relative humidity varying between 67 and $82 \%$ at altitudes varying between 970 and $2575 \mathrm{~m}$. Ideally, coffee trees have to be planted at altitudes below $2000 \mathrm{~m}$ (Wintgens 2009). Coffee fields are typically located in areas with slopes varying between 8 and $89 \%$. With regard to lithology, $63 \%$ of the coffee fields are established on soils developed on shale, and mica schist, $23.5 \%$ on granite and $9.7 \%$ on basic rocks. Very few fields $(1.4 \%)$ are established on volcanic soils with high base saturation and high $\mathrm{pH}$. Such soils provide considerable challenges for coffee production. The relationships between coffee growing and soil properties have been described by Nzeyimana et al. (2014). There are two main problems with soil fertility, (1) aluminium toxicity which is very often associated with low $\mathrm{pH}$ and low organic carbon content, (2) low levels of available phosphorous.

Coffee farmers require access to public and/or private transport facilities for the transport of both inputs (fertilisers, pesticides, mulch etc.) as well as outputs (coffee berries). 
Fig. 1 Coffee density (\%) within $5 \times 5 \mathrm{~km}$ grid. Ten main agroecological zones of Rwanda: (1) $K S$ Kivu lake shore, (2) IMP Impala, (3) IMB Imbo, (4) $C N D$ Congo-Nile watershed divide, (5) $M P B$ Mayaga plateau and Central Bugesera; (6) $C P$ Central Plateau, (7) ERP Eastern Ridge and Plateau, (8) EL Eastern Lowland, (9) $\mathrm{BH}$ Buberuka Highlands, (10) $V H P$ volcanoes and high plains. The country size is $26,338 \mathrm{~km}^{2}$. Photo of typical small holder coffee field near Lake Kivu. Coffee is typically grown on the higher slope segments, never on the valley floor
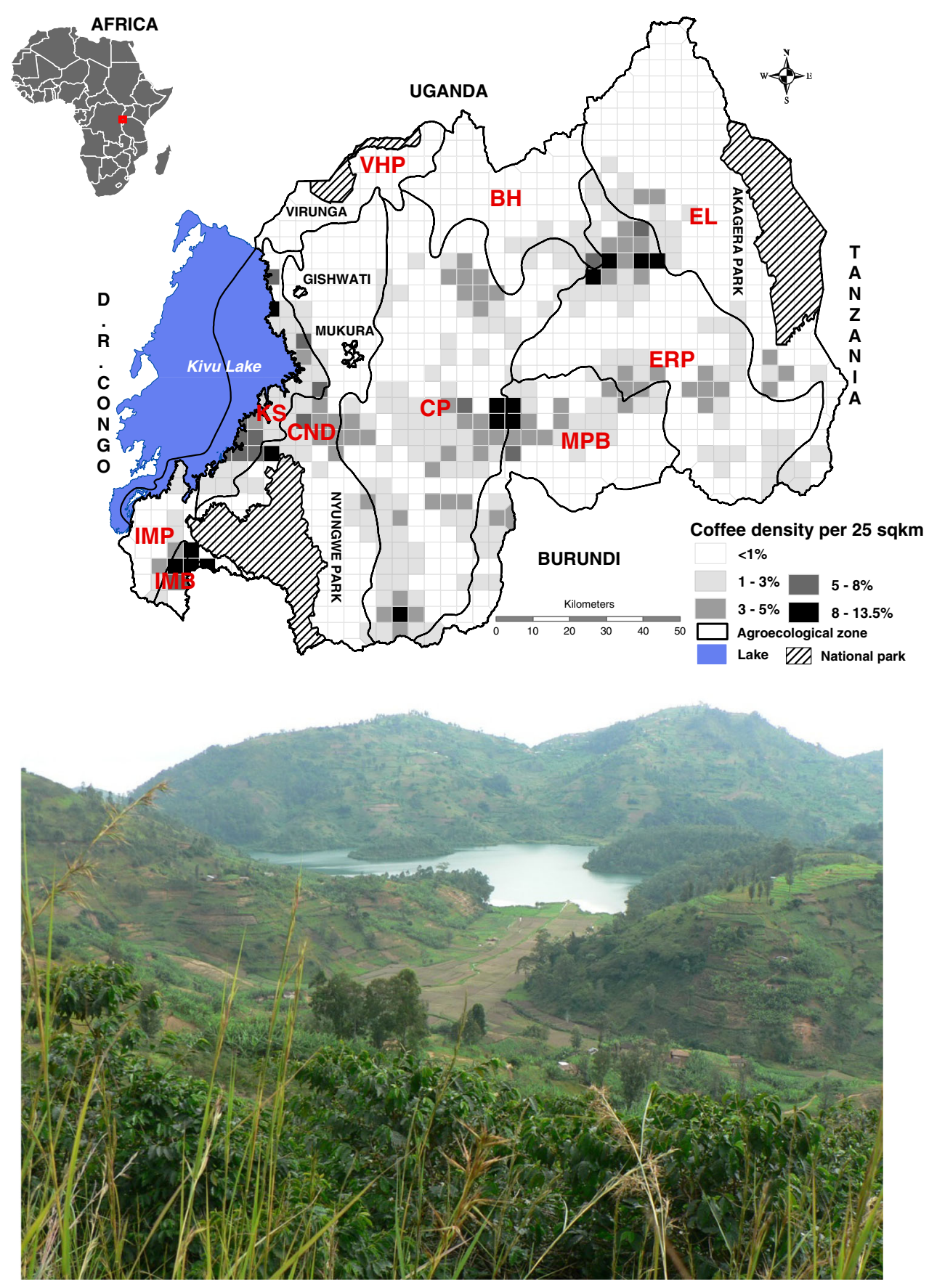

About $94 \%$ of coffee fields are located within $1 \mathrm{~km}$ from the primary and secondary roads. A different situation, however, unfolds if farmers have to travel to bring their coffee cherries to the nearest coffee washing station for processing. Only $9.3 \%$ of the coffee fields are located within $1 \mathrm{~km}$ distance from a coffee washing station. Even within the same region, cultural and social differences, and family size have been identified as important factors which influence farmers to grow coffee (Wintgens 2009). In Rwanda, due to land scarcity, the food security of a household generally takes priority over cash cropping.

\section{Material and methods}

\subsection{Biophysical and socio-economic data}

The biophysical and socio-economic data sources used in this study are briefly described:

1. Coffee fields data (i.e. location and size of fields with more than 200 coffee trees) was produced by Mukashema et al. (2014). The total of 119,513 coffee fields observed were randomly split into a training set 
$(59,757$ coffee plots) and a validation set $(59,756$ coffee plots). The randomising was done to avoid spatial autocorrelation and duplications of variables as advised by Overmars et al. (2003).

2. Soil data were acquired from the soil geo-database of Rwanda located at the Ministry of Agriculture and Animal Resources. This soil database is a result of a semi-detailed soil survey of Rwanda which started in 1981 and was finalised in 1994. A physical and chemical soil analysis was conducted for 1833 soil profiles spread over the country. The spatial interpolation of soil properties was done using landform data at the scale of 1:250, 000 and 1:50,000 (Verdoodt and Van Ranst 2006).

3. Climate data i.e. temperature, rainfall, relative humidity and potential evapotranspiration were obtained from the National Meteorological Service at the Ministry of Infrastructure. Average annual data were calculated for 183 weather stations using, for most stations, 60 years records from 1950 to 2010 . We interpolated these data using the thin-plate smoothing spline algorithm as proposed by Hijmans et al. (2005).

4. Topographic data i.e. altitude, hill shade, slope and aspect were generated by processing $10 \mathrm{~m}$-resolution digital terrain data produced using stereoscopy (See Mukashema et al. 2014).

5. Distances from each coffee field to infrastructural facilities were obtained by processing the data of coffee fields, GPS locations of coffee washing stations and the road network. The road network was earlier digitised using the topographic map of 1988 at a scale of 1:50,000 and updated by CGIS.

6. Population data of 2012 i.e. the total, density and age group originally recorded at the level of a 'cell' which is the smallest administrative unit in Rwanda (the size of a cell varies considerably (mean $11 \pm 18 \mathrm{~km}^{2}$ ).

\subsection{Statistical analysis}

Having information on the distribution of coffee plots (Mukashema et al. 2014), the identification of the environmental and human factors at coffee-growing locations becomes possible.

\subsubsection{Step 1: Extracting biophysical and socio-economic data at coffee locations}

The biophysical data and demographical data layers were rasterised into $10 \mathrm{~m}$ cells to allow comparison with the high resolution coffee field data. In total, 29 independent variables of which 22 are biophysical and nine socio-economic variables were extracted at each coffee field location and compiled in a GIS database for further spatial analysis.

\subsubsection{Step 2: Determining location drivers of coffee fields}

We first describe the 29 variables available at coffee field level. In order to reduce the number of variables, we applied principal component analysis (PCA) using the orthogonal Varimax rotation. Only variables with a PCA score of 0.5 and above are considered for further steps. Kaiser's criterion and communality measures are used to retain only factors with eigenvalues greater than 1 and variable communalities greater than 0.5 . Variables scoring higher than 0.7 of the total correlation are considered to indicate a fairly good consistency with the factor into which they are loaded. Only 17 variables remained in five independent factors for further analysis.

\subsubsection{Step 3: Explaining location variability of coffee fields}

We then evaluated with multiple linear regression as described by Austinet al. (1998) the extent to which the 17 remaining variables that explain the variability of current location $(x, y)$ of area (ha) occupied by coffee. This procedure was done for the country as a whole and separately for each agro-ecological zone. The area $\left(\mathrm{C}_{\text {ha }}\right)$ used for coffee cultivation is therefore determined by $\left(\mathrm{V}_{i(x, y)}\right)$ a number of biophysical and socioeconomic variables and their respective contribution $\left(b_{i}\right)$ as follows:

$C(h a)=b_{0}+\sum_{i=1}^{n} b_{i} V_{i(x, y)}$

Where, $b_{i}, i=0 \ldots n$ are coefficients obtained by stepwise (forward) regression. Variables $\mathrm{V}_{\mathrm{i}}$ with $b$ values which do not differ significantly from zero were dropped. Although the 'best' model is usually selected on the basis of goodnessof-fit $\left(R^{2}\right)$, we limited the maximum number of independent variables to ten in order to minimise noise in the models thus facilitating interpretation. Although the $b$ values and their significance are important estimates, standardised $b$ values $(\beta$, beta) are more explicit because they allow inter-comparison of the of factors within the regression model.

\subsubsection{Step 4: Predicting suitable areas for growing coffee}

We used the weighted coefficient variables from the specific regression models for the individual agro-ecological zones (AEZ) to determine potential areas for expanding or intensification of coffee cultivation. The model can also be used to identify areas where coffee is currently grown but which may not very suitable for the cultivation of coffee. Actual and predicted areas were standardised (in \%) using the maximum predicted area estimated by the AEZ specific models. The actual and predicted areas were compared using the validation dataset (i.e. $50 \%$ of the total coffee fields earlier separated from the training set). 


\subsection{Model validation}

The performance of the models (national and regional) was assessed by comparing the predicted suitable coffee locations with actual coffee-growing locations. First, spatial coffee data were randomly split into a training set $(59,757$ coffee fields) and a validation set $(59,756$ coffee fields). Second, the predicted outcomes were compared with the observed input and the difference map was produced, with mean error and $R^{2}$ calculated. The difference map shows where and in how far the model over- or underestimates suitable coffee-growing locations.

\section{Results and discussion}

\subsection{Location factors of coffee patterns}

Principal component analysis (PCA), revealed that 17 variables out of 29 load into five factors which explain $86 \%$ of the total variance in the total dataset. The factor loadings after rotation are shown in Table 1 including the not included variables. Population distribution and age constitute the first factor explaining $22.1 \%$ of the total variance in the dataset. The second factor which relates to climate and topography explains $20.6 \%$. The third factor represents the topsoil characteristics and fertility explains $17.8 \%$ of total variance. The fourth factor stands for the subsoil characteristics (i.e. soil lithology) and accounts for $14.8 \%$ of the total variance. The fifth factor is a mixture of physical soil properties and infrastructure and accounts for $10.7 \%$ of the total variance in the coffee dataset.

The reliability test revealed that 14 of the above 17 contributing variables are highly reliable $(r>0.7)$ in their respective factor loadings. Temperature and relative humidity are fairly reliable in the climate factor $\left(r_{t, \mathrm{RH}}<0.2\right)$, while the distance from the field to the nearest coffee washing station is only marginally reliable in the factor combining soil texture and infrastructure $\left(\mathrm{r}_{\mathrm{CWS}}=0.04\right)$ indicating that soil texture and coffee washing station facilities should be treated separately in the analysis.

\subsection{Explaining the current spatial distribution of coffee areas}

\subsubsection{Generalised national model}

The generalised linear model generated from the composite national coffee dataset explained only $9 \%$ of the total coffee area variability. This clearly indicates that a single model cannot properly explain the spatial distribution of coffee fields for Rwanda as a whole. Table 2 shows in detail the relationship between the current coffee areas and the biophysical and socio-economic factors. The coefficients ( $b$ values) of the generalised linear (GLM) model, standardised ( $\beta$ values, Fig. 2 ) variables and coefficients of determination $\left(R^{2}\right)$ are presented in Table 2.

As shown by the graphs of the standardised $\beta$ values (see Fig. 2), the national model is a composite of all five factors. The standardised $\beta$ values indicate the relative amount of change in coffee area size compared to an independent variable change. The graphs can be viewed as AEZ factor fingerprints of coffee-growing zones. They indicate which factors are important in which region. The generalised model has highest contributions from population youth $\left(\beta_{\mathrm{P} 16}=-0.4\right)$, and soil acidity $\left(\beta_{\mathrm{pH}}=0.3\right)$. Lesser contributions are made by atmospheric humidity and evapotranspiration $\left(\beta_{\mathrm{RH}}\right.$, PET $=-0.2)$, soil organic carbon $\left(\beta_{\mathrm{OC}}=0.2\right)$, and soil texture $\left(\beta_{\mathrm{Cy}, \mathrm{Sd}}=-0.2\right)$. For the national model, the figures indicate that all the factors are of equal importance. This confirms that the coffee field pattern is a function of complex interacting biophysical and socio-economic factors.

\subsubsection{Regionalized agro-ecological zone (AEZ) specific models}

The country was subsequently stratified into ten agroecological zones for which separate multiple linear regression models were made (see Table 2 and Fig. 2). Better model fits were achieved. For the Imbo (IMB) and Kivu islands (KI) the derived model explains up to $54 \%$ of the total coffee area variability. The model of the central plateau explained $34 \%$. In other zones, $28 \%$ of coffee areas found in the Buberukah Highlands (BH), $25 \%$ in the Congo-Nile watershed divide and $17 \%$ in Impala (IMP) were explained. Coffee cultivation along the lake Kivu shore (KLS), and the Eastern plateau and lowlands are poorly explained by biophysical and population factors $\left(R^{2}<10 \%\right)$.

Figure 2 summarises the standardised beta $(\beta)$ values of the significantly contributing variables at country level as well as at AEZ level. From west to east, the total population and the household size and age are an important factor in Kivu lake Shore (KS), and Impala (IMP) $(\beta=0.4-0.9)$. For the Kivu Islands (KI) with their highly fertile soils, the $N / K$ ratio is the only location factor explaining the pattern of coffee distribution. Similarly, in Imbo (IMB) and the Congo-Nile watershed Divide (CND), soil fertility is highly important $(\beta=0.4$ 1.3). In the Central Plateau (CP), topsoil fertility and subsoil properties are equally important. In $\mathrm{CP}$ the $\mathrm{N} / \mathrm{K}$ ratio has a higher degree of importance than other soil parameters $(\beta=-0.8)$. Climate has more influence on coffee location in the Buberuka Highlands (BH). In $\mathrm{BH}$, the negative effect of the atmospheric humidity $\left(\beta_{\mathrm{RH}}=-0.7\right)$ slows down the expansion of coffee growing. In the Mayaga, Bugesera (MPB), in the southeast, and the Eastern Lowlands (EL), the 
Table 1 Summary of principal component analysis results for the 29 variables at coffee locations

\begin{tabular}{|c|c|c|c|c|c|}
\hline \multirow[t]{2}{*}{ Variable items } & \multicolumn{5}{|c|}{ Rotated factor loadings } \\
\hline & 1 & 3 & 3 & 4 & 5 \\
\hline 1.Total population (PT) & 0.97 & 0.18 & 0.05 & 0.04 & 0.07 \\
\hline 2.Population under 16 years old (P16) & 0.94 & 0.20 & 0.06 & 0.07 & 0.04 \\
\hline 3.Population between 16 and 18 years old (P16-18) & 0.93 & 0.15 & 0.02 & 0.05 & -0.03 \\
\hline 4.Population with more than 18 years old (P18) & 0.95 & 0.15 & 0.03 & 0.02 & 0.10 \\
\hline 5.Potential evapotranspiration (PET mm.year ${ }^{-1}$ ) & 0.18 & 0.92 & 0.04 & 0.10 & -0.02 \\
\hline 6.Annual average temperature $\left(\mathrm{T}^{\circ} \mathrm{C}\right)$ & 0.17 & 0.91 & 0.09 & 0.14 & -0.10 \\
\hline 7.Annual relative humidity (RH \%) & -0.17 & -0.88 & -0.15 & -0.08 & -0.02 \\
\hline 8.Altitude (Alt m) & -0.17 & -0.83 & -0.14 & -0.23 & -0.02 \\
\hline 9.Soil total nitrogen $(\mathrm{N} \%)$ & 0.08 & 0.14 & 0.94 & 0.00 & 0.18 \\
\hline 10.Nitrogen-potassium ratio $(\mathrm{N} / \mathrm{K})$ & 0.03 & 0.03 & 0.90 & -0.33 & 0.12 \\
\hline 11.Soil organic carbon (SOC \%) & -0.03 & -0.17 & -0.86 & -0.31 & -0.08 \\
\hline 12.Soil $\mathrm{pH}$ water $(\mathrm{pHw})$ & 0.06 & 0.27 & 0.61 & 0.71 & -0.07 \\
\hline 13.Potassium content $\left(\mathrm{K} \mathrm{cmol}+. \mathrm{kg}^{-1}\right)$ & 0.09 & 0.19 & -0.12 & 0.86 & -0.04 \\
\hline 14.Calcium content $\left(\mathrm{Ca} \mathrm{cmol}+. \mathrm{kg}^{-1}\right)$ & 0.04 & 0.23 & 0.08 & 0.84 & -0.26 \\
\hline 15.Clay content $(\mathrm{Cy} \%)$ & -0.04 & 0.04 & -0.23 & 0.26 & -0.84 \\
\hline 16.Sand content $(\mathrm{Sd} \%)$ & 0.07 & 0.08 & 0.27 & -0.25 & 0.81 \\
\hline 17.Distance farm-coffee washing station (CWS in $\mathrm{m}$ ) & 0.07 & -0.13 & -0.15 & 0.38 & 0.56 \\
\hline Eigen values & 3.8 & 3.5 & 3.0 & 2.5 & 1.8 \\
\hline Percentage of variance explained & 22.1 & 20.6 & 17.8 & 14.8 & 10.7 \\
\hline Cumulative percentages & 22.1 & 42.6 & 60.5 & 75.3 & 86.0 \\
\hline
\end{tabular}

Significant variables are rotated by Varimax method. Five factors and 17 variables (1) population, (2) climate and topography, (3) topsoil soil fertility, (4) subsoil, (5) soil physical property and infrastructure are loaded with eigenvalues greater than 1 and variable communality greater than 0.7 except for the distance of farm to coffee washing station (CWS) variable which has a communality of 0.5 . The percentage of variance explained by each factor is also presented. Valid $\mathrm{N}$ list wise $=53,255$ coffee field

Not included variables: population density people $\left./ \mathrm{km}^{2}\right)$, rainfall $\left(\mathrm{mm} . \mathrm{year}^{-1}\right)$, Hill shade (-), slope aspect (degree), slope (\%), pH_KCl, C/N ratio, CEC clay (cmol. $\left.\mathrm{kg}^{-1}\right), \mathrm{Al}\left(\mathrm{cmol}_{\mathrm{kg}}{ }^{-1}\right), \mathrm{Mg}\left(\mathrm{cmol}_{\mathrm{kg}}{ }^{-1}\right), \mathrm{P}$ (ppm) road distance to coffee field $(\mathrm{m})$ population factor is more important than climate and soil factors $\left(\beta_{P}=0.4-0.8\right)$.

\subsection{Analysing potential locations for coffee expansion}

Potential areas for coffee cultivation for the whole country were identified using the regional multiple regression models. This was done under the assumption that when the model based on local biophysical and socio-economic conditions, indicates higher coffee field densities than currently observed, there is potential for more coffee fields within the current land use systems. In Fig. 3, the calculated potential coffee location areas are presented as percentage of the total arable land. There are five classes of occurrence: $0 \%$ no coffee, $0-25 \%$, 25-50\%, 50-75\% and 75-100\% coffee occurrence. Assuming that a lower calculated coffee area percentage indicates a lower suitability with respect to the analysed location factors we can also indicate where coffee is grown under suboptimal conditions. Figure 3 presents the actual coffee fields (a), potential coffee-growing areas according to the national model (b) and according to the regional models (c) and the areas where according to the regional models, coffee area increase is possible (d). These changes include expanding $(+)$ or reducing $(-)$ of coffee field density as a consequence of good or poor environment and socio-economic conditions.

For comparison purposes and to link to the still commonly used land evaluation classes, we propose to label the following: $0 \%$ calculated coffee predicted area as unsuitable and not remediable (N2), 0-25\% as unsuitable but remediable (N1), $25-50 \%$ as marginally suitable (S3), $50-75 \%$ as moderately suitable (S2) and 75-100 \% as suitable (S1). Strictly speaking this is not correct but it allows some grounds for comparison. The map (Fig. 3) shows few areas where coffee suitability appears to be very high. Those areas are Kivu lake Shore, central and south Plateau and Mayaga. Smaller suitable areas are visible in the eastern ridge and plateau as well as the Buberuka highlands (in Burera-Ruhondo region). The least suitable areas are the Congo-Nile watershed divide.

The actual coffee field occurrence (Fig. 3a) is compared with the predicted coffee area suitability (Fig. 3c). Of the 
Table 2 Coefficients $(b)$ quantifying the contribution each variable to the current coffee areas (ha) distribution are presented

\begin{tabular}{|c|c|c|c|c|c|c|c|c|c|c|c|c|}
\hline \multicolumn{2}{|c|}{ Factors and variables } & \multirow[t]{2}{*}{ Nation } & \multicolumn{10}{|c|}{ Agro-ecological zones } \\
\hline & & & $\mathrm{KI}$ & $\mathrm{KS}$ & IMP & IMB & CND & $\mathrm{CP}$ & $\mathrm{BH}$ & MPB & ERP & EL \\
\hline \multirow{5}{*}{$\begin{array}{l}\text { Constant } \\
\text { Population }\end{array}$} & & 32.6 & -0.7 & -8.4 & 21.4 & 10.9 & 32.9 & 18.3 & 101.6 & 60.5 & -2.9 & -39.1 \\
\hline & P16 & $4.10^{-3}$ & & & & $-5.10^{-3}$ & & 0.01 & -13 & $4.10^{-4}$ & & \\
\hline & P16-18 & -0.02 & & -0.01 & & 0.02 & 0.02 & -0.04 & & & -0.02 & -0.01 \\
\hline & P18 & & & 3.10 & -5.1 & & -5.1 & & & & $1.10^{-3}$ & $2.10^{-3}$ \\
\hline & PT & & & & $10^{-3}$ & & & & & $-10^{-3}$ & & $-10^{-3}$ \\
\hline \multirow{4}{*}{$\begin{array}{l}\text { Topography } \\
\text { and Climate }\end{array}$} & Alt & & & & $-5.10^{-3}$ & 0.01 & & & & -0.02 & $3.10^{-3}$ & 0.01 \\
\hline & $\mathrm{T}$ & & & 0.43 & -0.63 & 3.57 & -1.01 & 1.14 & & & & 0.42 \\
\hline & RH & -0.52 & & & & & & -1.3 & -1.01 & & & 0.16 \\
\hline & PET & -0.01 & & & & -0.04 & -0.01 & -0.01 & -0.01 & -0.01 & & -0.01 \\
\hline \multirow[t]{4}{*}{ Topsoil } & SOC & 0.58 & & & -0.4 & -4.47 & & & -1.26 & & & \\
\hline & $\mathrm{N}$ & & & & & & -1.11 & 1.07 & & -0.24 & & \\
\hline & $\mathrm{N} / \mathrm{K}$ & & 0.13 & & & -2.58 & 0.25 & -0.55 & -0.15 & & 0.05 & \\
\hline & $\mathrm{pH}$ & 4.78 & & & & & & 21.06 & & -1.77 & & \\
\hline \multirow[t]{4}{*}{ Subsoil } & $\mathrm{Ca}$ & -0.44 & & -0.07 & -0.06 & -0.37 & & -5.55 & -1.15 & & & -0.08 \\
\hline & $\mathrm{K}$ & & & & & -28.43 & & 22.8 & & & & \\
\hline & $\mathrm{Sd}$ & -0.13 & & 0.03 & & & -0.14 & -0.29 & & & -0.04 & \\
\hline & $\mathrm{Cy}$ & -0.19 & & & & 0.45 & & -0.31 & & -0.21 & & \\
\hline \multirow[t]{2}{*}{ Infrastructure } & CWS & & & $-2.10^{-4}$ & $2.10^{-4}$ & $10^{-3}$ & $-10^{-4}$ & & & $4.10^{-4}$ & & \\
\hline & Adj. $R^{2}$ & 0.09 & 0.52 & 0.1 & 0.17 & 0.54 & 0.25 & 0.34 & 0.28 & 0.11 & 0.08 & 0.19 \\
\hline
\end{tabular}

Each agro-ecological zone specific linear models for each (AEZ) has all $b$ values significant at $P<0.001$. The adjusted goodness of fits (Adj. $R^{2}$ ) is also presented. The standardised betas are listed in Fig. 2

$K S$ Kivu lake shore, IMP Impala, IMB Imbo, $C N D$ Congo-Nile watershed divide, $M P B$ Mayaga plateau and Central Bugesera, $C P C$ Central Plateau, $E R P$ Eastern Ridge and Plateau, EL Eastern Lowland, $B H$ Buberuka Highlands, $V H P$ volcanoes and high plains, $P T$ total population, $P 16$ population under 16 years old, $P 16-18$ population between 16 and 18 years old, $P 18$ population with more than 18 years old, $P E T$ potential evapotranspiration, $T$ annual average temperature, $R H$ annual relative humidity, Alt altitude, $N$ soil total nitrogen, $N / K$ nitrogen-potassium ratio, $S O C$ soil organic carbon, $p H w$ soil $\mathrm{pH}$ water, $K$ potassium content, $C a$ calcium content, $C y$ clay content, $S d$ sand content, $C W S$ distance farm-coffee washing station

actual coffee fields $6.6 \%$ is located in 'unsuitable' areas (N2 and N1), $33.4 \%$ in marginally suitable (S3) areas, $57.3 \%$ in moderately suitable (S2) areas and $2.7 \%$ in suitable areas (S1). So altogether, $60 \%$ of the existing coffee fields are located in moderately suitable to suitable areas.

\subsection{Exploring spatial coffe distribution}

\subsubsection{Role of environmental and socio-economic factors in coffee field density}

Rwandan coffee systems are clearly driven by both regional socio-economic and environmental factors. These factors play out differently in the ten agro-ecological zones. Climatic (temperature) and topographic (altitude) factors play a prominent role in Imbo and Kivu lake shore in the western part of Rwanda. In this area, an increase of 3 ha of coffee area is observed as the elevation decreases by $200 \mathrm{~m}$ and the temperature increases by $1.2{ }^{\circ} \mathrm{C}$ (towards the border of lake Kivu). Potential evapotranspiration plays a modest role in the Congo-Nile divide, the central plateau and Buberuka highland, the Mayaga plateau and eastern lowlands. It indicates that in these regions the coffee system appears to be more climate sensitive than in other regions.

Soils play also a prominent role in determining coffee location within the whole country. Although we expected aluminium toxicity and phosphorous levels to play an important role, it was not included in any of the regressions, but the related $\mathrm{pH}$ was. The most important soil factor is the nitrogen-potassium ratio of the soil. This ratio reflects the interface between nutrient availability in the topsoil and the inherent chemical properties of the subsoil. The more significant contribution is found in central western part of the country. In many regions (Kivu lake shore, Impala, Imbo, central plateau, Buberuka highlands and eastern low lands), the soil acidity $\mathrm{pH}$ and calcium depletion of the subsoil has a negative effect on the occurrence of coffee. A combination of lime, agroforestry, organic and mineral fertiliser could improve soil fertility for such highly depleted acidic soils (Bucagu et al. 2013).

Soil texture (sand and clay content) plays only a minor role in the spatial distribution of coffee. Except in the Kivu lake 


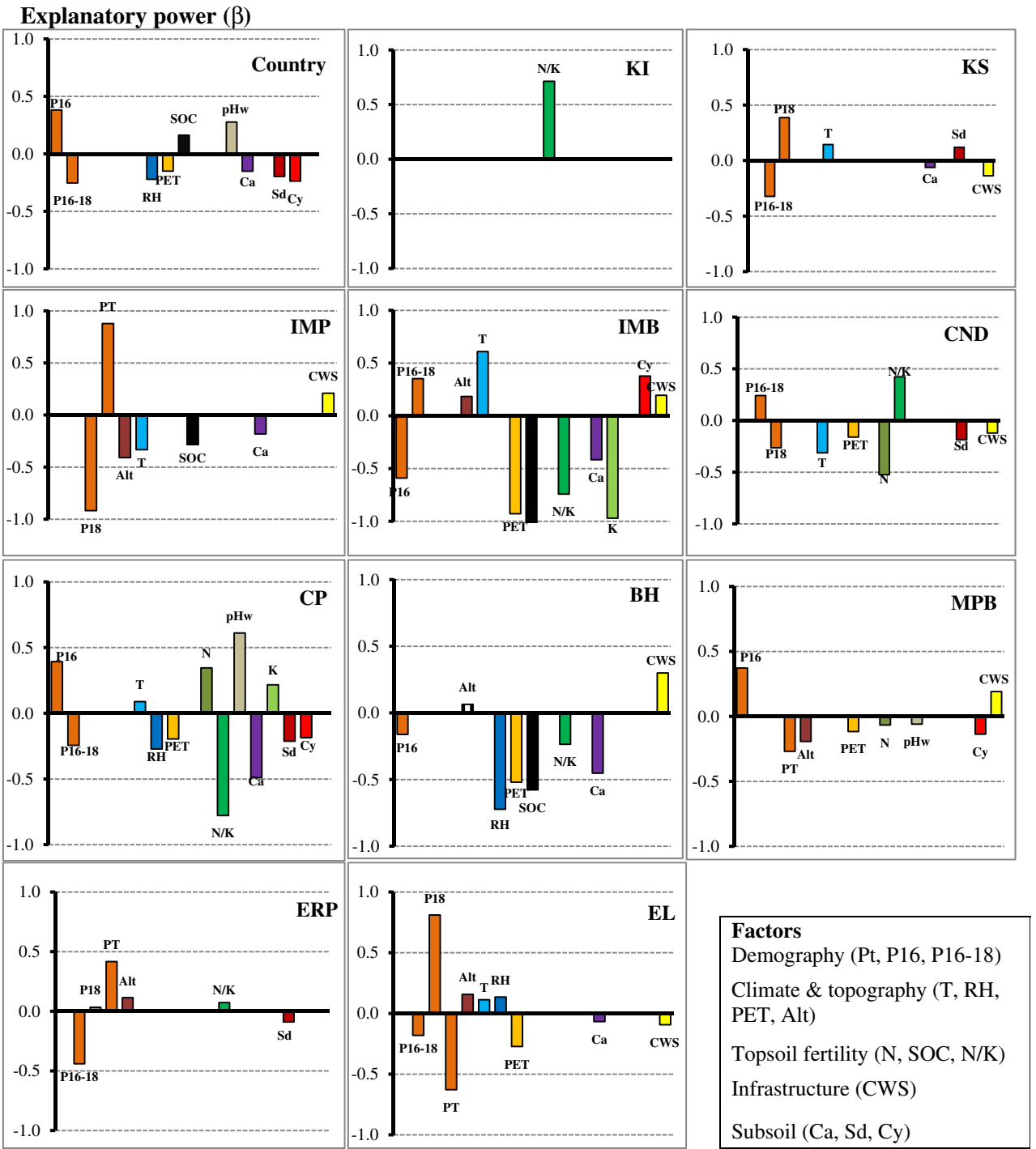

Significant variable

Fig. 2 Explanatory power ( $\beta=$ standardised 'b' values) of biophysical and human variables loading in the five main components (factors) at country level and at agro-ecological zone level (factor label see table 1). The beta standardised $(\beta)$ allow inter-comparison of relative contribution of various factors such climate, soil, fertility, demographic and infrastructure development in respective agricultural zones. It gives factor 'fingerprint' of the location factors. National $R^{2}=0.09$, KI $R^{2}=0.52 ; \mathrm{KS} R^{2}=0.10$; IMP $R^{2}=0.17$; IMB $R^{2}=0.54$; CND $R^{2}=0.25 ; \mathrm{CP} R^{2}=0.34 ; \mathrm{BH} R^{2}=0.28 ; \mathrm{MPB} R^{2}=0.11 ; \mathrm{ERP} R^{2}=0.08$; EL $R^{2}=0.19$. KS Kivu lake shore, IMP Impala, IMB Imbo, CND Congo-

shore area where sand and clay content has a positive effect on coffee occurrence; a negative effect is observed in the eastern Nile divide zones.

The importance of soil derived properties gives some merit to the soil-based approach used by Nzeyimana et al. (2014). Their methodology, however, clearly leaves out relevant socioeconomic coffee factors that are most dynamic or prone to change.
Nile watershed divide, $M P B$ Mayaga plateau and Central Bugesera, $C P$ Central Plateau, ERP Eastern Ridge and Plateau, EL Eastern Lowland, $B H$ Buberuka Highlands, $V H P$ volcanoes and high plains, $P T$ total population, $P 16$ population under 16 years old, $P 16-18$ population between 16 and 18 years old, $P 18$ population with more than 18 years old, $P E T$ potential evapotranspiration, $T$ annual average temperature, $R H$ annual relative humidity, Alt altitude, $N$ soil total nitrogen, $N / K$ nitrogenpotassium ratio, $S O C$ soil organic carbon, $p H w$ soil $\mathrm{pH}$ water, $K$ potassium content, $\mathrm{Ca}$ calcium content, $\mathrm{Cy}$ clay content, $S d$ sand content, CWS distance farm-coffee washing station

The coffee production infrastructure plays a modest contribution in most regions with the exception of the eastern ridge and plateaus and Buberuka highlands. In the area where there are more coffee washing stations (see Fig. 2), a positive contribution to coffee area can be observed while in the more remote areas with less coffee washing stations, a negative contribution is observed. This suggests that coffee washing stations can stimulate coffee production in their neighbourhood. This is related to a 

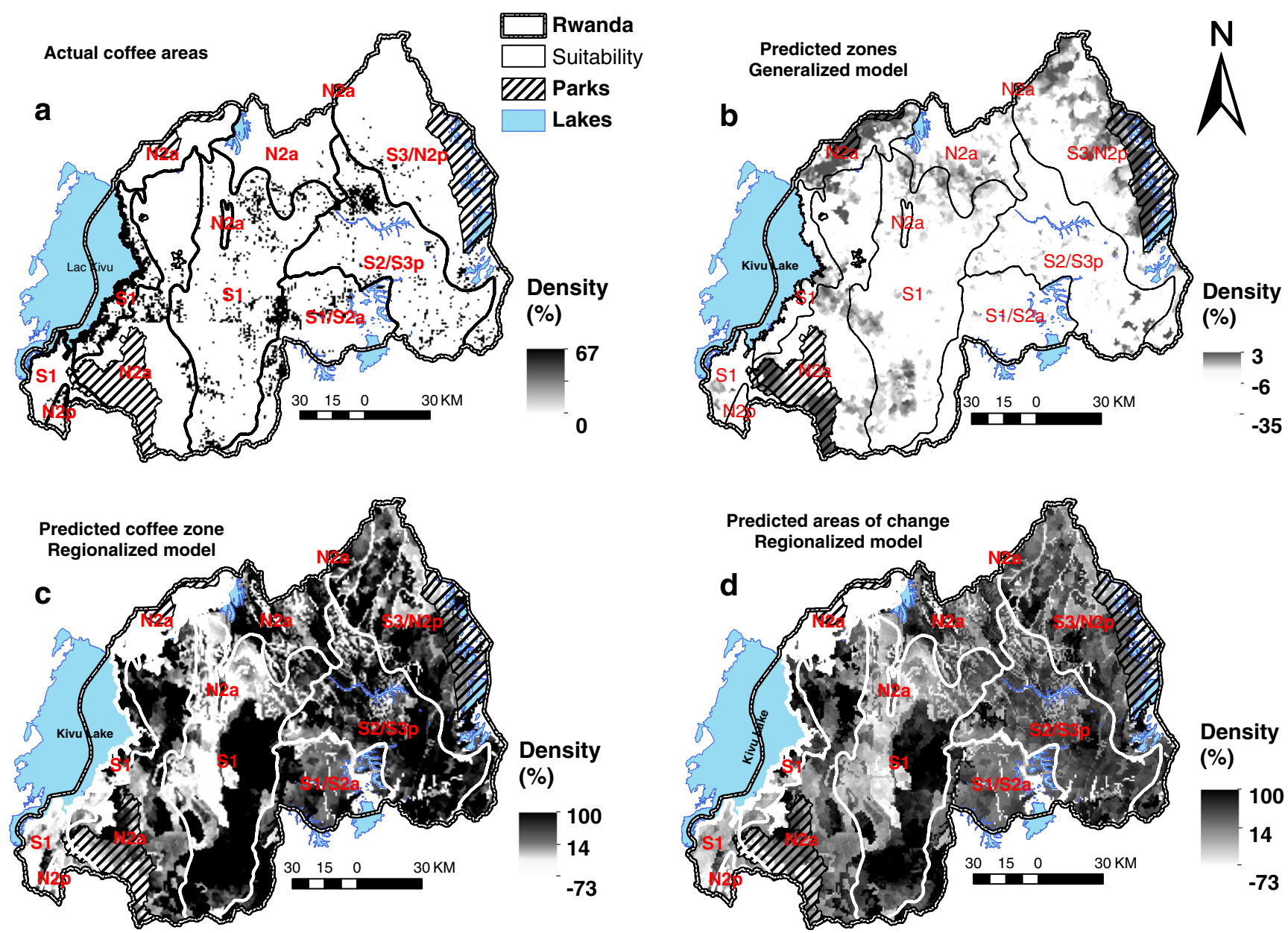

Fig. 3 Actual coffee field density (a), predicted coffee density maps by the generalised (b) and regionalized (c) models compared with the actual density of coffee (a) mapped using high resolution imagery (Mukashema et al. 2014). The difference of actual and predicted are (d) explicitly visualises potential areas change. The scale from negative $(-)$ to positive $(+)$ change indicates where actual coffee area densities are

governmental project for initiating coffee washing stations that started in 2002 with pilots with cooperatives in South province (example of Maraba coffee). Government of Rwanda provided cooperatives with advisory work on the development of business plans, strengthened organisation and building linkages with coffee buyers and financial institutions. By 2010 this had become a programme with 183 washing stations.

Population density and associated labour availability have a strong association with the occurrence of coffee in Kivu lake shore area, Impala, Imbo, Mayaga, eastern ridge and plateau. The other central regions have more modest contribution of demography. When in the future other types of socio-economic data, such a transport distances/costs for fertilisers and coffee prizes become available, we expect an improved system understanding.

Our systematic analysis clearly demonstrates that coffee field distribution is part of a complex land use system where not only many different factors play a significant role, but where locally larger $(+)$ to lower $(-)$ than expected by location factors. The traditional suitability (from S1 to N2) map (Verdooth and Ransk 2006) is overlaid to calculated map. The country size is $26,338 \mathrm{~km}^{2}$. For presentation, the resolution has been reduced to the grid cell size of 7 by 7 acres which correspond to the mean variance of coffee plots

different trade-off decisions are made. Coffee fields are often not located on the biophysical optimal location due to the equal importance of socio-economic factors and the competition with other land use functions. This difference explains why current coffee density (Fig. 1) and the modelled coffee density maps (Fig. 3) do not resemble the predicted potential coffee map (Fig. 3, Nzeyimana et al. 2014).

\subsubsection{Modelling coffee distribution}

The regional models all have different variable contributions from the environmental and human-related factors. This reflects the regional diversity as discussed earlier. The coefficients of determination $\left(R^{2}\right)$ range between 10 and $54 \%$. The fit of the regression models improves when using a more detailed spatial stratification of the country. This confirms that coffee system analysis is a very scale and context sensitive exercise (Veldkamp et al. 2001). 
Regional models were used to calculate coffee occurrence for the whole country. This resulted in a probability map displaying areas ranging from 0 to $100 \%$ coffee occurrence (Fig. 3). When comparing this probability map with the traditional biophysical land evaluation map (Fig. 3a), it is obvious that the probability map displays much more detail and spatial variability. It is also important to realise that the probability map is based upon factors which in reality can change quickly over time. Dynamic processes such as population mobility (within 5-10 years), soil management (5-10 years), climate change (decadal), infrastructure and coffee washing station construction (5-10 years) can be easily accommodated by the methodology presented here by recalculating a new probability map using updated factor data. It is also important to mention that it is possible to include additional factors in the analysis if such data becomes available.

\subsubsection{Potential areas for future coffee expansion}

Potential areas for coffee expansion according to the regression models are shown in (Fig. 3d). South of the Congo-Nile watershed divide, east of Nyungwe forest, a potentially suitable area is visible. However, this area is used for tea production since many decades. This represents a good example of how the land use history and land use causes suboptimal utilisation of land from one commodity perspective. An additional suitable coffee area is observed in the northern part of the Congo-Nile watershed divide. In this area, protected forest is the predominant land use (Westinga et al. 2013). Another suitable area for coffee growing is located in the east and north east. This area used to be within the Akagera National park. After 1995, this area was rezoned to allow human resettlement, pasture and large-scale maize cultivation. In the western part of Buberuka highlands, another suitable area is identified. However, this is a traditional wheat growing area. Also in some central parts of the country, highly suitable lands are visible. In these areas, the absence of coffee is explained by the vicinity of the rapidly growing city of Kigali and its satellite cities. In a similar fashion highly suitable locations are found near to urbanising areas such as Rwamagana and Bugesera (located in the southeast) and Muhanga and Huye (located in the central and southern parts of the country). This matches the global trend that cities eat up very suitable agricultural land (Haller 2014). In summary, all potentially suitable coffee areas outside current coffee regions have other rational reasons than poor suitability to grow coffee. Causes are either related to competition with other land uses or a specific land use history. Despite of the above, the regionalized model fit (Fig. 3) is satisfactory (60\%). The model outputs also demonstrate that a significant proportion of coffee cultivation $(40 \%)$ is actually grown in less suitable locations (40\%). Translocating this coffee to more suitable locations might increase coffee production. Given the previously discussed limitations on coffee expansion to new areas, it might be a more realistic option to intensify coffee production. We propose to reanalyse the coffee system on a regular basis to allow more sustainable recommendations about planned changes in coffeegrowing areas.

\section{Conclusions}

Biophysical and socio-economic factors together determine the spatial pattern of coffee growing in Rwanda. The main potential explanatory factors of coffee can be statistically grouped into five main components: (1) socio-economic demographic factors, (2) local climate and topography, (3) topsoil fertility, (4) subsoil properties and (5) physical soil properties and coffee production infrastructure. Multiple regression analysis using these variables for the whole country explains only $9 \%$ of the total variability of coffee field occurrence. Spatially disaggregate models using different regional dependent combinations of explanatory variables resulted in a much improved explanatory power of spatial coffee field variability (adj. $R^{2}$ arising to $54 \%$ ). In general, the smaller the region the better the model fit. This suggests a high diversity in local factors determining coffee field distribution.

The regionalized models were subsequently used to model coffee occurrence for the whole country. This demonstrated that $60 \%$ of current coffee fields are located at suitable locations. The remaining fields are situated in less suitable locations. The modelling exercise suggests, given all model limitations, that there are still potentially suitable coffee areas available in the country. But many highly suitable areas are already occupied by other competing uses. Given the very limited land resources in Rwanda, it appears to be more realistic to increase future coffee production not so much by expansion of the coffeegrowing area as a whole but rather via a process of substitution whereby coffee cultivation is intensified at suitable locations. In less suitable locations, coffee growing could be reduced or converted into more suitable land uses.

Acknowledgments We thank the Dutch government through the Netherlands Fellowship Programme for the financial support.

Open Access This article is distributed under the terms of the Creative Commons Attribution 4.0 International License (http:// creativecommons.org/licenses/by/4.0/), which permits unrestricted use, distribution, and reproduction in any medium, provided you give appropriate credit to the original author(s) and the source, provide a link to the Creative Commons license, and indicate if changes were made.

\section{References}

Austin EJ, Willock J, Deary IJ, Gibson GJ, Dent JB, Edwards-Jones G, Morgan O, Grieve R, Sutherland A (1998) Empirical models of farmer behaviour using psychological, social and economic variables. Part I: linear modelling. Agric Syst 58:203-224. doi:10. 1016/S0308-521X(98)00066-3 
Boudreaux K, Ahluwalia P, (2009) Cautiously optimistic: economic liberalization and reconciliation. in Rwanda's Coffee Sector-Denv. J. Int'l L. \& Pol'y, 2008 - HeinOnline

Bucagu C, Vanlauwe B, Giller KE (2013) Managing Tephrosia mulch and fertilizer to enhance coffee productivity on smallholder farms in the Eastern African Highlands. Eur J Agron 48:19-29. doi:10.1016/ j.eja.2013.02.005

Haller A (2014) The "sowing of concrete": Peri-urban smallholder perceptions of rural-urban land change in the Central Peruvian Andes. Land Use Policy 38:239-247. doi:10.1016/j.landusepol.2013.11. 010

Hernandez-Martinez G, Manson RH, Hernandez AC (2009) Quantitative classification of coffee agroecosystems spanning a range of production intensities in central Veracruz, Mexico. Agric Ecosyst Environ 134:89-98. doi:10.1016/j.agee.2009.05.020

Hijmans RJ, Cameron SE, Parra JL, Jones PG, Jarvis A (2005) Very high resolution interpolated climate surfaces for global land areas. Int $\mathrm{J}$ Climatol 25:1965-1978. doi:10.1002/joc. 1276

Lambin EF, Turner BL, Geist HJ, Agbola SB, Angelsen A, Bruce JW, Coomes OT et al (2001) The causes of land-use and land-cover change: moving beyond the myths. Glob Environ Chang 11:261269. doi:10.1016/S0959-3780(01)00007-3

Mukashema A, Veldkamp A, Vrieling A (2014) Automated high resolution mapping of coffee in Rwanda using an expert Bayesian network. Int J Appl Earth Obs Geoinf 33:331-340. doi:10.1016/j.jag. 2014.05.005

Murekezi AK (2009) Essays on the effects of coffee market reforms, supply chains, and income improvement in Rwanda. Agricultural Economics, Michigan State University, p 127

National Institute of Statistics of Rwanda (NISR), M.o.F.a.E.P.M.R. (2012) Rwanda Fourth Population and Housing Census. MINECOFIN, Kigali, p 256

Nsengiyumva F, (2009) Rwanda National Coffee Census. In: OCIRCAFE/NAEB (Ed.), Kigali, Rwanda, p. 76.

Nyandwi E, Veldkamp A, Amer S, (2016) Regional climate sensitivity of wetland environments in Rwanda: the need for a location specific approach. Regional Environmental Change (in press) DOI: 10.1007/ s10113-015-0905-z

Nzeyimana I, Hartemink AE, de Graaff J (2013) Coffee farming and management in Rwanda. Outlook on Agriculture 42:47-52. doi: 10.5367/oa.2013.0118
Nzeyimana I, Hartemink AE, Geissen V (2014) GIS-based multi-criteria analysis for Arabica Coffee expansion in Rwanda. PLoS ONE 9(10), e107448. doi:10.1371/journal.pone.0107449

Overmars KP, de Koning GHJ, Veldkamp A (2003) Spatial autocorrelation in multi-scale land use models. Ecol Model 164:257-270. doi: 10.1016/S0304-3800(03)00070-X

UNEP (2011) Rwanda: from post-conflict to environmentally sustainable development. United Nations Environment Programme, Nairobi

Veldkamp A, Fresco LO (1997) Reconstructing land use drivers and their spatial scale dependence for Costa Rica (1973 and 1984). Agric Syst 55:19-43. doi:10.1016/S0308-521X(95)00080-O

Veldkamp A, Verburg PH, Kok K, de Koning GHJ, Priess J, Bergsma AR (2001) The need for scale sensitive approaches in spatially explicit land use change modeling. Environmental Modeling Assessment 6: 111-121. doi:10.1023/A:1011572301150

Verbist B, Dinata Putra AE, Budidarsono S (2005) Factors driving land use change: effects on watershed functions in a coffee agroforestry system in Lampung, Sumatra. Agric Syst 85:254-270. doi:10.1016/ j.agsy.2005.06.010

Verburg PH, Veldkamp A (2001) The role of spatially explicit models in land-use change research: a case study for cropping patterns in China. Agric Ecosyst Environ 85:177-190. doi:10.1016/S01678809(01)00184-0

Verdoodt A, Van Ranst E (2006) Environmental assessment tools for multi-scale land resources information systems - a case study of Rwanda. Agric Ecosyst Environ 114:170-184. doi:10.1016/j.agee. 2005.10.006

Verwimp P (2003) The political economy of coffee, dictatorship, and genocide. Eur J Polit Econ 19:161-181. doi:10.1016/S01762680(02)00166-0

Westinga E, Mukashema A, van Gils H (2013) A comparison of fine resolution census and image-based national forest inventories: a case study of Rwanda. Forestry 86:453-461. doi:10.1093/forestry/ cpt016

Wintgen JN (2009) Coffee: growing, processing, sustainable production. A guidebook for growers, processors, traders, and researchers. WILEY-VCH Verlag GmbH \& Co. KGaA, Weinheim, p 983. ISBN 978-3-527-32286-2 